\title{
ASSESSMENT OF ANATOMICAL VARIATIONS OF MEDIAN LINGUAL CANALS: A CBCT STUDY
}

\author{
Dina F. Ahmed* and Ahmed M. Abd Alsamad**
}

\begin{abstract}
Objectives: To investigate the presence, the number, the anatomic location, the course and morphology of median lingual canals in edentulous patients using cone beam computed tomography (CBCT).

Subjects and methods: Fifty completely edentulous patients were recruited from the outpatient clinic of the Prosthodontics Department, Faculty of Dentistry, Cairo University. All patients in this study were seeking to improve the retention of their mandibular complete dentures through dental implants. Patients were of age ranging from 50 to 70 years. A CBCT scan was performed for all patients to evaluate the edentulous area prior to implant placement. The number, the anatomical location and morphology of the median lingual canals were assessed by two Oral and Maxillofacial Radiologists. Additionally, the slope of the canals, the distance between the alveolar crest and the terminal ends of the median lingual canals; the length and the diameter of the median lingual canals were also assessed.
\end{abstract}

Results: All patients had at least one median lingual canal. Supra-spinosum canals were more frequent than infra-spinosum canals. Regarding the anatomical lingual canal morphology, Type E, A and D showed the greatest frequency. Most of the supra-spinosum canals sloped downward toward the labial surface, while most of the infra-spinosum canals sloped upward toward the labial surface. The distance between the buccal terminal end of the canal and the alveolar crest ranged between (3.6 - $21.2 \mathrm{~mm}$ ) for supra-spinosum canals and $(9.4-24.8 \mathrm{~mm})$ for infra-spinosum canals. The distance between the lingual terminal end of the canal and the alveolar crest ranged between (2.7 - $19.4 \mathrm{~mm})$ for supra-spinosum canals and $(10.8-30.4 \mathrm{~mm})$ for infra-spinosum canals. The canal length was found to be $(3.5-15.3 \mathrm{~mm})$ for supra-spinosum canals and $(2.4-10.2 \mathrm{~mm})$ for infra-spinosum canals. The average diameter of all canals ranged between $(0.4-1.2 \mathrm{~mm})$.

Conclusions: Determination of the number, the position as well as the diameter of median lingual canals before mandibular midline implant surgery in edentulous patient is important as these canals are constant anatomical landmark which have both vascular and neurosensory components.

* Lecturer of Oral and Maxillofacial Radiology, Faculty of Dentistry, Cairo University.

** Associate Professor of Oral and Maxillofacial Radiology, Faculty of Dentistry, Cairo University. 


\section{INTRODUCTION}

Accurate identification of important anatomical structures during the pre-operative stage of the implant procedure helps the clinician to avoid complications during surgery. Several reports indicated neurovascular complications following surgical interventions in the mandibular midline region ${ }^{1,2}$. Cone beam computed tomography has been shown to be superior to conventional radiographic techniques in displaying the mandibular lingual canals ${ }^{2,3}$. Previous studies showed variations in number, location, morphological appearance of these canals in humans from different geographical regions ${ }^{4}$. To date, several studies have described the midline lingual canals in different races $^{5-7}$. However, no studies investigated the frequency, location, morphological variations as well as linear measurements of the midline lingual canals in an Egyptian population.

\section{SUBJECTS AND METHODS}

This study included 50 completely mandibular edentulous patients who were recruited from the outpatient clinic of the Prosthodontics department, Faculty of Dentistry, Cairo University. CBCT scans were taken for all patients as part of their preoperative assessment for implant supported rehabilitation. The age of the patients ranged from 50 to 70 years. 38 patients were males and 12 patients were females. Patients with any systemic conditions that contraindicates implant placement were excluded from the study. Exclusion criteria also included bone pathology in the mandibular region. An informed consent had to be signed and approved by all patients before CBCT imaging and implant installation. The study proposal was approved from the Ethical committee of Faculty of Dentistry Cairo University since 13 June 2016 (Ethical Approval Number: 16/6/10).

The CBCT scans were obtained by Planmeca Pro Max 3D Mid (Helsinki, Finland) at the Oral and Maxillofacial Radiology Department, Faculty of Dentistry, Cairo University using the standard patient positioning protocol. All patients were scanned using a tube potential of $90 \mathrm{kVp}$, a tube current of $10 \mathrm{~mA}$, a cylindrical field of view of $20 \times 6 \mathrm{~cm}$ and a voxel size of $400 \mu \mathrm{m}$. The acquired images were processed with Romexis software and measurements were taken using the measurement tools of Romexis software under magnification and brightness and contrast adjustment. The scans were analyzed in a PC running Microsoft Windows 10 (Microsoft Corp, Redmond, WA, USA). All the observations and measurements were carried out by two Oral Radiologists experienced in CBCT scan interpretation.

In order to detect the median lingual canals, the midline had to be determined. In literature, the midline was defined as the line running between the pogonion and the apex of the mental spine of each mandible ${ }^{6}$. The midline was drawn on the axial image from the convexity of genial tubercle (mental spine) to the mental ridge. In order to standardize the procedure, the slice thickness and the spacing between all cuts were adjusted at $0.4 \mathrm{~mm}$. Five consecutive sagittal cuts on each side of the midline were carefully used for the assessment of the following aspects:

\section{I- The appearance and morphological varia- tions of median lingual canals}

\section{1- The presence and number of median lingual} canals: The canals were further classified according to their relation to the mental spine into supra-spinosum for canals that open above the mental spine and infra-spinosum for canals that open below the mental spine.

2- The anatomical lingual canal morphology: The classification suggested by Abesi et al. ${ }^{8}$ was used (Figure 1).

Agreement between the two Oral and Maxillofacial Radiologists was used for the assessment of the appearance and morphological variations of the genial spinal canals. 


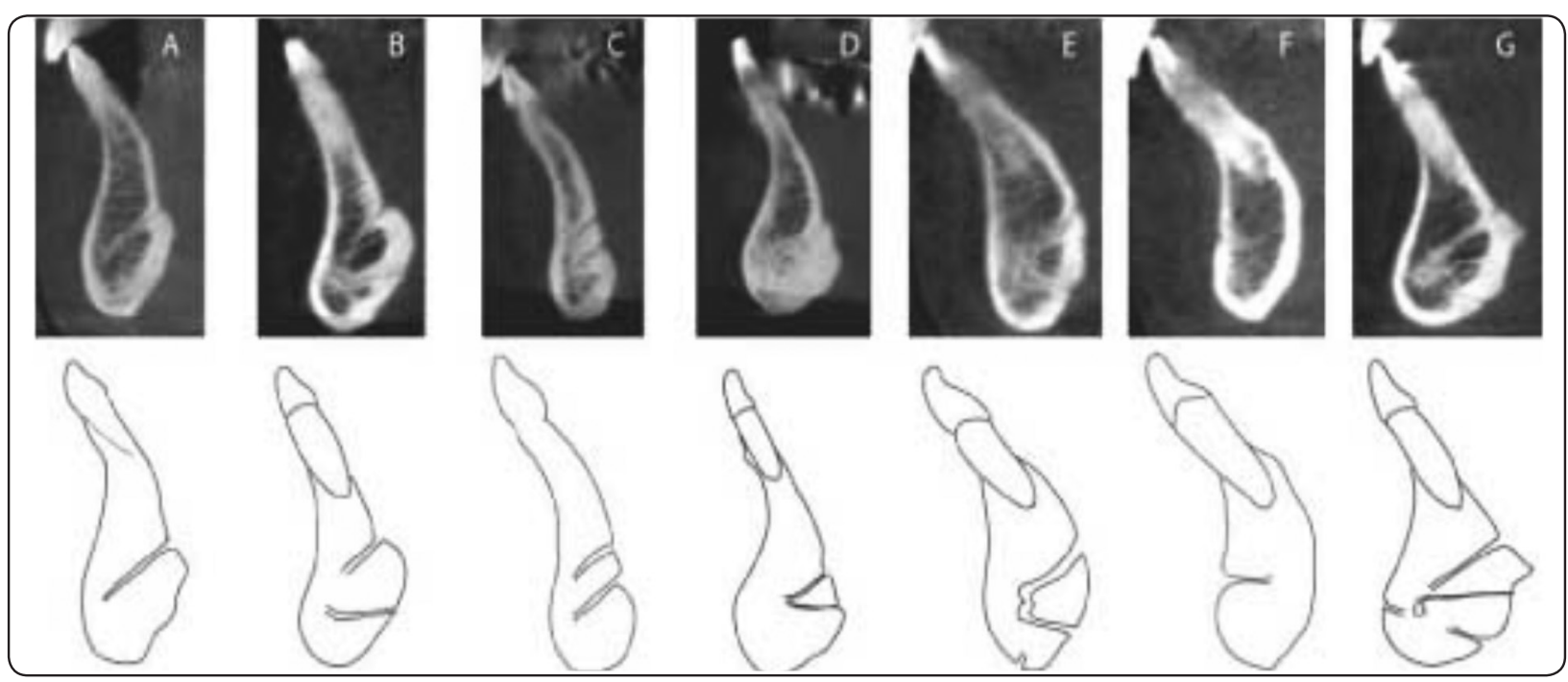

Fig. (1) The classification of canal morphology by Abesi et al. ${ }^{8}$

\section{II- Linear measurements}

1- Distance between the upper border of both the buccal and lingual terminal ends of each canal and the alveolar crest.

2- Length of each canal.

3- Diameter of both lingual and buccal terminal ends of each canal.

The average readings of the two Oral and Maxillofacial Radiologists were taken for the assessment of the linear measurements.

\section{RESULTS}

\section{1) Gender and age:}

In this study, males were predominant with 38 (76\%) while females were 12 (24\%). Mean value of age of all participants was $(60.3 \pm 5)$ years with minimum of 50 years and maximum of 70 years.

\section{2) Number and location of canals:}

Each patient showed at least one canal. Supraspinosum canal was found in 49 patients where 8 of them showed 2 foramina. The mean value of canal number was (1.1 \pm 0.4$)$. Infra-spinosum canal was found in 38 patients where 10 of them showed 2 foramina. The mean value of canal number was

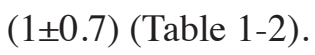

TABLE (1) The number of Supra-spinosum and Infra-spinosum canals

\begin{tabular}{|c|c|c|c|}
\hline & $\begin{array}{c}\text { Total number } \\
\text { of patients } \\
\text { with canal }\end{array}$ & $\begin{array}{c}\text { Number of } \\
\text { patients with } \\
\text { one foramen }\end{array}$ & $\begin{array}{c}\text { Number of } \\
\text { patients with } \\
\text { two foramina }\end{array}$ \\
\hline $\begin{array}{c}\text { Supra- } \\
\text { spinosum } \\
\text { canal }\end{array}$ & $49 / 50$ & 41 & 8 \\
\hline $\begin{array}{c}\text { Infra- } \\
\text { spinosum } \\
\text { canal }\end{array}$ & $38 / 50$ & 28 & 10 \\
\hline
\end{tabular}

TABLE (2) The number and percentage of patients with different number of Median Lingual Canals

\begin{tabular}{|c|c|c|}
\hline & Number & Percentage \\
\hline Patients with one foramen & 10 & $20 \%$ \\
\hline Patients with two foramina & 28 & $56 \%$ \\
\hline Patients with three foramina & 9 & $18 \%$ \\
\hline Patients with four foramina & 3 & $6 \%$ \\
\hline
\end{tabular}




\section{3) Anatomical lingual foramen morphology:}

For the lingual canal morphology, 18 patients (36\%) showed type E followed by 7 patients (14\%) showed type A, followed by 7 patients (14\%) showed type D, followed by 3 patients (6\%) showed type B where 15 patients $(30 \%)$ showed other morphologies than those suggested by Abesi et al. ${ }^{8}$ in their classification (Figure 2-4).

\section{4) Canal Slope:}

In supra-spinosum canals, $93 \%$ of the canals sloped downwards in the vertical direction (slope direction is from lingual surface to labial surface),

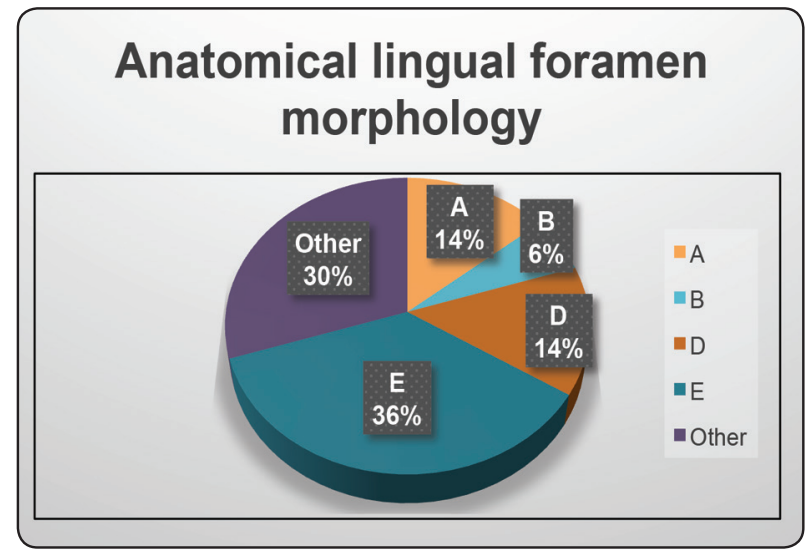

Fig. (2) Pie chart showing the number and percentage of the different lingual canal morphologies in our study $3.5 \%$ of the canals sloped upwards and $3.5 \%$ of the canals were horizontal.

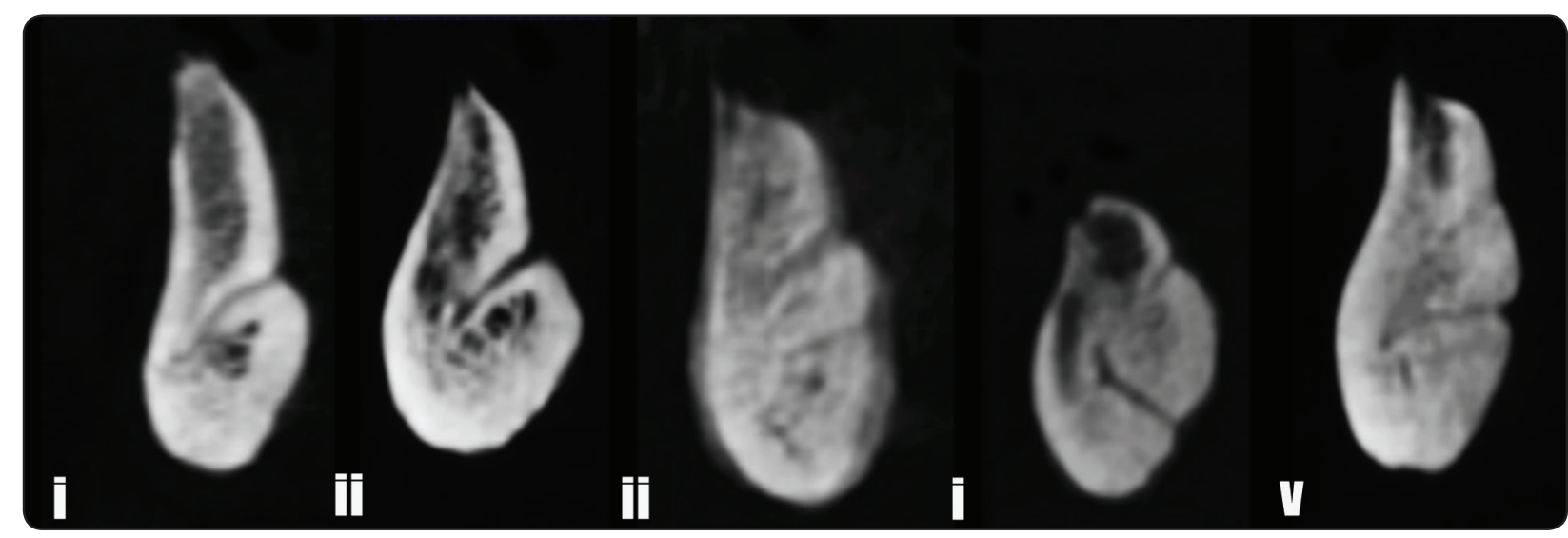

Fig. (3) CBCT images showing morphology of lingual canal where images (i) \& (ii) represent type A, image (iii) represents type $\mathrm{B}$, image (iv) represents type $\mathrm{E}$, image (v) represents type D.

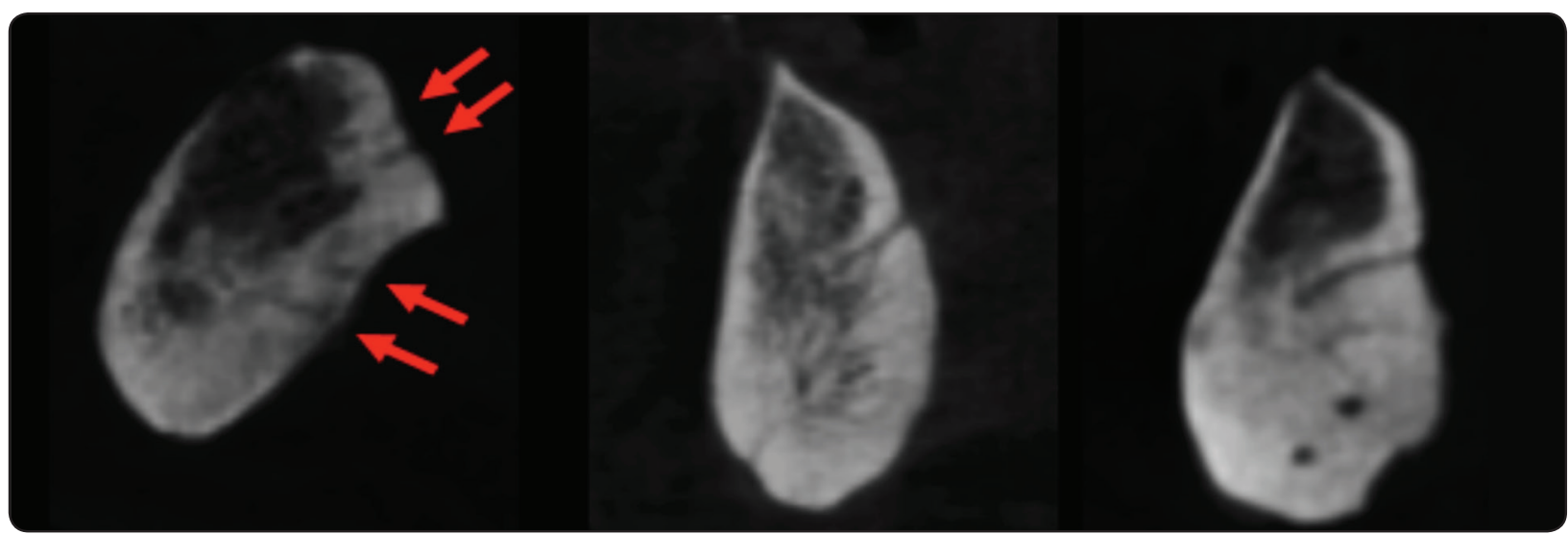

Fig. (4) CBCT images showing morphology of lingual canal other than the classification of Abesi et al. ${ }^{8}$ 
For infra-spinosum canals, $75 \%$ of the canals sloped upwards in the vertical direction (slope direction is from lingual surface to labial surface) while $6 \%$ of the canals sloped downwards and $19 \%$ were horizontal.

\section{5) Distance between upper border of the buccal terminal and alveolar crest:}

The mean value of distance between upper border of the buccal terminal and alveolar crest in supra-spinosum canals was $(14.4 \pm 4.2 \mathrm{~mm})$ with a range of (3.6- $21.2 \mathrm{~mm})$. The infra-spinosum canals showed mean value of $(16.5 \pm 4.4 \mathrm{~mm})$ with a range of (9.4- $24.8 \mathrm{~mm})$.

\section{6) Distance between upper border of the lingual terminal and alveolar crest:}

The mean value of distance between upper border of the lingual terminal and alveolar crest in supra-spinosum canals was $(9.6 \pm 3.8 \mathrm{~mm})$ with a range of (2.7 - $19.4 \mathrm{~mm})$. The infra-spinosum canals showed mean value of $(19.9 \pm 4.8 \mathrm{~mm})$ with a range of $(10.8-30.4 \mathrm{~mm})$.

14 patients $(28 \%)$ showed a distance more than $12 \mathrm{~mm}$ between the highest point of the canal and the crest of alveolar ridge, while 36 patients (72\%) showed a distance less than $12 \mathrm{~mm}$ between the highest point of the canal and the crest of alveolar ridge (Table 3 ).
TABLE (3) The number and percentages of patients with bone height greater and lesser than $12 \mathrm{~mm}$

\begin{tabular}{|c|c|}
\hline $\begin{array}{c}\text { Number of patients with } \\
\text { more than } \mathbf{1 2} \mathbf{~ m m}\end{array}$ & $\begin{array}{c}\text { Number of patients with } \\
\text { less than } \mathbf{1 2} \mathbf{~ m m}\end{array}$ \\
\hline 14 patients $(28 \%)$ & 36 patients $(72 \%)$ \\
\hline
\end{tabular}

\section{7) Canal Length:}

The mean value of canal length in supraspinosum canals was $(8.8 \pm 2.1 \mathrm{~mm})$ with a range of (3.5 -15.3 mm). The infra-spinosum canals showed a mean value of $(7.1 \pm 1.7 \mathrm{~mm})$ with a range of $(2.4$ - $10.2 \mathrm{~mm})$.

\section{8) Diameter of Lingual terminal:}

The mean value of diameter of lingual terminal of supra-spinosum canals was $(0.6 \pm 0.2 \mathrm{~mm})$ with a range of (0.4 -1.1 mm). The infra-spinosum canals showed mean value of $(0.6 \pm 0.2 \mathrm{~mm})$ with a range of (0.4 - $1.2 \mathrm{~mm})$.

\section{9) Diameter of Buccal terminal:}

The mean value of diameter of buccal terminal of supra-spinosum canals was $(0.6 \pm 0.2 \mathrm{~mm})$ with a range of (0.4 -1.1 mm). The infra-spinosum canals showed mean value of $(0.5 \pm 0.2 \mathrm{~mm})$ with a range of $(0.4-1 \mathrm{~mm})$.

TABLE (4) The mean, standard deviation and range of the different linear measurements.

\begin{tabular}{|l|l|c|c|}
\hline \multicolumn{2}{|l|}{ Linear Measurements } & Mean \pm SD & Range \\
\hline \multirow{2}{*}{ Distance upper border of the buccal terminal and alveolar crest } & Supra-spinosum & $14.4 \pm 4.2 \mathrm{~mm}$ & $3.6-21.2 \mathrm{~mm}$ \\
\cline { 2 - 4 } & Infra-spinosum & $16.5 \pm 4.4 \mathrm{~mm}$ & $9.4-24.8 \mathrm{~mm}$ \\
\hline \multirow{2}{*}{ Distance upper border of the Lingual terminal and alveolar crest } & Supra-spinosum & $9.6 \pm 3.8 \mathrm{~mm}$ & $2.7-19.4 \mathrm{~mm}$ \\
\cline { 2 - 4 } & Infra-spinosum & $19.9 \pm 4.8 \mathrm{~mm}$ & $10.8-30.4 \mathrm{~mm}$ \\
\hline \multirow{2}{*}{ Canal Length } & Supra-spinosum & $8.8 \pm 2.1 \mathrm{~mm}$ & $3.5-15.3 \mathrm{~mm}$ \\
\cline { 2 - 4 } & Infra-spinosum & $7.1 \pm 1.7 \mathrm{~mm}$ & $2.4-10.2 \mathrm{~mm}$ \\
\hline \multirow{2}{*}{ Diameter of Lingual terminal } & Supra-spinosum & $0.6 \pm 0.2 \mathrm{~mm}$ & $0.4-1.1 \mathrm{~mm}$ \\
\cline { 2 - 4 } & Infra-spinosum & $0.6 \pm 0.2 \mathrm{~mm}$ & $0.4-1.2 \mathrm{~mm}$ \\
\hline \multirow{2}{*}{ Diameter of Buccal terminal } & Supra-spinosum & $0.6 \pm 0.2 \mathrm{~mm}$ & $0.4-1.1 \mathrm{~mm}$ \\
\cline { 2 - 4 } & Infra-spinosum & $0.5 \pm 0.2 \mathrm{~mm}$ & $0.4-1 \mathrm{~mm}$ \\
\hline
\end{tabular}




\section{DISCUSSION}

With the increased use of dental implants to replace missing teeth in the jaws, the number of implants used in the mandibular anterior region also increased. The anatomic structures in this area have recently gained attention as several studies reported hemorrhage with the possibility of airway obstruction as well as sensory disturbances after implant preparation in the midline mandibular region ${ }^{\mathbf{9 1 0}}$. A search in the literature even revealed a few cases of life-threatening bleeding following surgical procedures in this area ${ }^{11}$. Different cadaveric studies reported that neurovascular structures enter the mandible through the foramina in the lingual side of the midline region of the mandible, although its contents are still a matter of debate ${ }^{12,13}$. The variability of the location and morphology of these canals as well as its clinical significance may stress the importance of its accurate radiographic identification and description. The identification of the midline lingual foramina and its canals has significantly improved with the use of 3-D imaging techniques used for preoperative planning of dental implants ${ }^{14}$. Different investigators found it difficult to locate the median lingual canals on conventional radiographic techniques. McDonnell et al. stated that these canals have an inclined path in relation to the lingual surface of the mandible and therefore if the $\mathrm{x}$-ray beam is not aligned parallel to the long axis of the canal, then it would not show on the resultant radiograph ${ }^{15}$. In their study this was the case in $49 \%$ of the specimens. Poyton and Pharoah also reported that only a small number of intra-oral radiographs could show the median lingual foramina ${ }^{\mathbf{1 6}}$. Jacobs et al.added that also observer experience may affect the ability to detect the median lingual foramina on conventional radiographs ${ }^{17}$. Furthermore; it is possible that race and ethnic background may show differences in the anatomy of these canals ${ }^{18}$.

In contrast to 2-D imaging, CBCT imaging is not affected by beam orientation and therefore the identification of these canals was easy in our study.
The presence of median lingual canals was found in all of our cases. This was in accordance with a number of previous studies in which the frequency of the midline lingual canals ranged between (98$100 \%)^{2,4,15,19}$. However, other studies showed a slightly lower frequency of these canals ${ }^{20,21}$. The reason why the frequency of median lingual canals was higher in our study is may be due to the high spatial resolution of the CBCT images. Another reason may be the anatomical variations among people from different regions. However, in a CT study by Jacobs et al., the median lingual canals were found in only $82 \%$ of the images ${ }^{17}$. A possible explanation for this discrepancy is that the CT scans do not provide reformatted cross-sectional cuts exactly in the midline mandibular region. Another reason might be the $1 \mathrm{~mm}$ slice thickness which may mask the canals of smaller diameters.

Regarding the different locations of median lingual canals, we found that supra-spinosum canals were present in 49 of our patients $(98 \%)$ where 8 of them showed two canals. Infra-spinosum canals were found in 38 patients (76\%) where 10 of them showed two canals. Sheikhi et al. also showed very similar results ${ }^{5}$. They reported that the frequencies of the supra-spinosum canals and infra-spinosum canals were $99 \%$ and $74.5 \%$ respectively. Although with slightly different frequencies (87\% Supraspinosum and $84 \%$ Infra-spinosum), Kawei et al. also showed higher frequency for supra-spinosum than infra-spinosum canals ${ }^{6}$. However, Ebrahimi et al. reported considerably lower frequencies for both supra and infra-spinosum canals $(80.3 \%$ and $32.7 \%$ respectively) ${ }^{7}$. The clinical significance that our study showed that $98 \%$ of the median lingual canals are in a position superior to the mental spine and having a long path is the great possibility of its penetration during implant surgery. The same risk can also be seen if the slope of the canal is directed upwards. Furthermore, among our patients, the presence of two lingual foramina for median lingual canal was the most frequent $(56 \%)$. This was the case in a number of other studies, ${ }^{2,19,22}$. On 
the contrary, Liang et al. and Tepper et al. found that a single lingual foramen was more frequent ${ }^{23,24}$. Our study comes also in agreement with Katakami et al. in that some patients showed up to 4 midline lingual foramina ${ }^{25}$. However, in clinical practice, the distance from the alveolar crest, not the number, is the factor to be considered to avoid the possible complications.

In our study we used the classification proposed by Abesi et al. ${ }^{8}$ for the assessment of the lingual canal morphology. 36\% of our patients showed type E, $14 \%$ showed type A, $14 \%$ showed type $\mathrm{D}, 6 \%$ showed type $\mathrm{B}$ and $30 \%$ showed different morphologies than those suggested by Abesi et al. ${ }^{8}$ (Figure 2-4). However, our results were different from those obtained by Abesi et al. ${ }^{8}$. They showed that most of their patients were type B (54\%) and A $(39.5 \%)$. Again, the different ethnic background is probably the cause of this discrepancy.

In our study we found that most $(93 \%)$ of the supra-spinosum canals sloped downwards in the vertical direction (slope direction is from lingual surface to labial surface) while only $3.5 \%$ sloped upwards and the same percentage ran horizontally. For infra-spinosum canals, $75 \%$ of these canals sloped upwards in the vertical direction (slope direction is from lingual surface to labial surface), $19 \%$ of the canals were horizontal while only $6 \%$ sloped downwards. Sheikhi et al. and Kawai et al. also stated the majority of the superior lingual canals were running downward to the labial side ${ }^{6}$. The clinical significance of the assessment of the canal slope is that the upward slope direction is more liable for injury during implant insertion.

According to the results of this study, the mean value of the distance between the alveolar crest and the upper border of the buccal terminal in supraspinosum canals was $(14.4 \pm 4.2 \mathrm{~mm})$. In case of infraspinosum canals our results showed a mean value of $(16.5 \pm 4.4 \mathrm{~mm})$. We also found that the mean value of distance between upper border of the lingual terminal and alveolar crest in supra-spinosum canals was $(9.6 \pm 3.8 \mathrm{~mm})$. For the infra-spinosum canals the mean value was $(19.9 \pm 4.8 \mathrm{~mm})$. Currently, the most commonly used implant length in the midline mandibular region is $10 \mathrm{~mm}^{26,27}$, and a safety margin of $2 \mathrm{~mm}$ is recommended ${ }^{28}$. Therefore, the distance from the alveolar crest should be more than $12 \mathrm{~mm}$ in order not to injure the nearby neurovascular structures. Our results suggest that the lingual terminal of supra-spinosum canals is more liable of being injured during implant surgery. In addition, only $28 \%$ of our patients showed a distance of more than $12 \mathrm{~mm}$ between the highest point of the canal and the crest of alveolar ridge, while the majority $72 \%$ showed a distance less than $12 \mathrm{~mm}$ between the highest point of the canal and the crest of alveolar ridge. These result were different from those obtained by $\mathrm{He}$ et al. who found that only $32 \%$ of their patients showed a vertical distance less than $12 \mathrm{~mm}^{29}$. The reason of this discrepancy might be that all of our patients were edentulous and crestal bone resorption occurs soon after extraction. Hereby we recommend that a CBCT scan should be performed prior to implant installation in this region to avoid violation of these canals.

Regarding the length of the canals, we found that the mean length of supra-spinosum canals was $(8.8 \pm 2.1 \mathrm{~mm})$ and that of the infra-spinosum canals was $(7.1 \pm 1.7 \mathrm{~mm})$. These results were close to those obtained by Sheikhi et al.5. Similarly, the 50 dry mandibles examined by Liang et al. showed a slightly smaller mean value for the length of both superior and inferior canals ${ }^{4}$.

A number of previous studies also measured the diameter of the midline lingual canals. They stated that the diameter of these canals is the factor that determines the risk of severe bleeding when traumatized. They assume that the diameter of these canals is proportional to the diameter of the artery passing through. They stated that arteries greater than $1 \mathrm{~mm}$ are more likely to cause severe bleeding or major hematoma ${ }^{2,6,29}$. The present study showed 
that the mean value of the diameter of lingual terminal of both the supra and infra-spinosum canals was $(0.6 \pm 0.2 \mathrm{~mm})$. The mean value of the diameter of the buccal terminal of both supra and infraspinosum canals was $(0.6 \pm 0.2 \mathrm{~mm})$ and $(0.5 \pm 0.2$ $\mathrm{mm}$ ) respectively. Different results were obtained by Sheikhi et al. who stated that the diameter of the superior and inferior lingual foramen on CBCT images were $(1.12 \pm 0.3 \mathrm{~mm})$ and $(0.9 \pm 0.39 \mathrm{~mm})$ respectively ${ }^{5}$. However, an anatomical study on dry mandible gave only a slightly larger mean diameter of the midline foramina on the lingual side of mandibles $(0.8 \pm 0.4 \mathrm{~mm})$ than our study ${ }^{23}$.Similarly, Rosano et al. in another anatomical study showed 0.8-0.9 mm diameter of the lingual foramen ${ }^{2}$. Our results were closest to those of Gahleitner et al. who stated that the mean value of the midline lingual canals was $(0.7 \pm 0.3 \mathrm{~mm})^{3}$. The small differences between the studies might be due to the different origin of the study group. We also assume that the reason our study showed the smallest mean diameter of the canals, is that all of our patients were edentulous.

\section{CONCLUSIONS}

CBCT was able to depict the variations in the midline mandibular canals. CBCT scans showed that the mandibular median lingual canal is a constant finding in the midline region of the mandible. In our study supra-spinosum canals were more frequent than infra-spinosum canals and two foramina were also more frequent than single midline lingual foramen. Most of the supra-spinosum canals sloped downwards while most of the infra-spinosum canals sloped upwards toward the labial side. In this study, CBCT also showed different morphologies of the midline lingual canals than previous studies. Linear measurements should be carefully evaluated prior to implant placement in the mandibular anterior region to avoid canal penetration and its accompanied complications.

\section{REFERENCES}

1. Hirsch JM, Branemark PI. Fixture stability and nerve function after transposition and lateralization of the inferior alveolar nerve and fixture installation. Br J Oral Maxillofac Surg. 1995; 33:276 81.

2. Rosano G, Taschieri S, Gaudy JF, Testori T, Del Fabbro M, Anatomic assessment of the anterior mandible and relative hemorrhage risk in implant dentistry: A cadaveric study. Clin Oral Implants Res 2009; 20(8):791-795.

3. Gahleitner A, Hofschneider U, Tepper G, Pretterklieber M, Schick S, Zauza K, Watzek G, Lingual vascular canals of the mandible: evaluation with dental CT. Radiology, 2001; 220(1):186-189.

4. Liang X, Jacobs R, Corpas LS et al. Chronologic and geographic variability of neurovascular structures in the human mandible. Forensic Sci Int 2009; 190: 24-32.

5. Sheikhi M, Mosavat F, Ahmadi A. Assessing the anatomical variations of lingual foramen and its bony canals with CBCT taken from 102 patients in Isfahan. Dental Research Journal, 2012; 9: 45-51.

6. Kawei T, Asaumi R, Sato I et al, Classification of the lingual foramina and their bony canals I the median region of the mandible: CBCT observations of dry Japanese mandibles, Oral Radiol 2007, 23: 42-48.

7. Ebrahimi M, Pripatnanont P, Omami G, Tharanon W, CBCT analysis of Mental and Genial Spinal Foramina in a Thai population, IJDOS 2015; 2(4):65-71.

8. Abesi F, Ehsani M., Haghanifar S, Sohanian S, Assessing anatomical variations of lingual foramen and its bony canals with CBCT. IJSBAR 2015; 20(1): 220-227.

9. Mardinger O, Manor Y, Mijiritsky E, et al: Lingual perimandibular vessels associated with life-threatening bleeding: An anatomic study. Int J Oral Maxillofac Implants2007; 22:127, 2007.

10. Boys-Varley JG, Lownie JF. Haematoma of the floor of the mouth following implant placement. SADJ 2002; 57:64-65.

11. Woo, B.M., Al-Bustani, S. \& Ueeck, B.A. Floor of the mouth hemorrhage and life-threatening airway obstruction during immediate implant placement in the anterior mandible. International Journal of Oral and Maxillofacial Surgery 2006; 35: 961-964.

12. Tagaya A, Matsuda Y, Nakajima K, et al, Assessment of the blood supply to the lingual surface of the mandible for reduction of bleeding during implant surgery. Clin Oral Implants Res 2009; 20:351-357. 
13. Givol N, Chaushu G, Halamish-Shani T, Taicher S. Emergency tracheostomy following life-threatening hemorrhage in the floor of the mouth during immediate implant placement in the mandibular canine region. $\mathrm{J}$ Periodontol 2000; 71:1893-5.

14. Harris D, Buser D, Dula K, Grondahl K, Harris D, Jacobs R, et al. E.A.O. guidelines for the use of diagnostic imaging in implant dentistry. A consensus workshop organized by the European Association for Osseointegration in Trinity College Dublin. Clin Oral Implants Res 2002; 13:566-70.

15. McDonnell D, Reza Nouri M, Todd ME.The mandibular lingual foramen: a consistent arterial foramen in the middle of the mandible. J Anat 1994; 184:363-369

16. 16- Poyton H, Pharoah M (1989) Oral radiology, 2nd edn. Decker, Toronto, pp 56-59

17. Jacobs R, Wu CH, Van Loven K, Desnyder M, Kolenaar B, Van Steenberghe D.Methodology of oral sensory tests. J Oral Rehabil 2002; 29:720-730.

18. Kaufman E, Serman NJ, Wang PD. Bilateral mandibular accessory foramina and canals: A case report and review of the literature. Dentomaxillofac Radiol 2000; 29:170-175.

19. Vanderwelle G, Liang X, Jacobs R, Lambrichts I, Macroanatomic and Radiologic Characteristics of the Superior Genial Spinal Foramen and its bony canals. Int J Oral Maxillofac Implants 2006; 21: 581-586.

20. Sekerci AE, Sisman Y, Payveren MA. Evaluation of location and dimensions of mandibular lingual foramina using cone-beam computed tomography. Surg Radiol Anat 2014; 36: 857-864.

21. Kim D, Kim M, Kim C. Distribution of the lingual foramina in mandibular cortical bone in Koreans. J Korean
Assoc Oral Maxillofac Surg 2013; 39: 263-268.

22. Von Arx T, Matter D, Buser D, Bornstein M, Evaluation of location and dimensions of lingual foramina using limited CBCT, JOral Maxillifac Surg 2011; 69:2777-2785.

23. Liang X, Jacobs R, Lambrichts I, et al. Lingual foramina on the mandibular midline revisited: A macroanatomical study. Clin Anat 2007; 20: 246-251.

24. Tepper G, Hofschneider UB, Gahleitner A, Ulm C. Computed tomographic diagnosis and localization of bone canals in the mandibular interforaminal region for prevention of bleeding complications during implant surgery. Int J Oral Maxillofac Implants 2001; 16: 68-72.

25. Katakami K, Mishima A, Kuribayashi A, et al. Anatomical characteristicsof the mandibular lingual foramina observed on limited CBCT images. Clin Oral Implants Res 2009; 20:386

26. Romeo E, Ghisolfi M, Rozza R et al. Short (8-mm) dental implants in the rehabilitation of partial and complete edentulism: A 3-to 14-year longitudinal study. Int J Prosthodont 2006; 19: 586-592.

27. Monje A, Chan H-L, Fu J-H et al. Are short dental implants $(<10 \mathrm{~mm})$ effective? A meta-analysis on prospective clinical trials. J Periodontol 2013; 84: 895-904.

28. Oettle AC, Fourie J, Human-Baron R et al. The midline mandibular lingual canal: importance in implant surgery. Clin Implant Dent Relat Res 2015; 17: 93-101.

29. Xuejiao He, Junqiang Jiang, Wei Cai et al, Assessment of the appearance, location and morphology of mandibular lingual foramina using CBCT, International Dental Journal 2016; $220: 1-8$. 